\title{
Tools for Forming an Effective Industry Structure of Mining Region
}

\author{
Fares Abu-Abed ${ }^{1 *}$, and Oleg Ostanin ${ }^{2}$ \\ ${ }^{1}$ Tver State Technical University, A. Nikitin Street, 22, 170026, Tver, Russia \\ ${ }^{2}$ T.F. Gorbachev Kuzbass State Technical University, 650000, 28 Vesennyaya St., Kemerovo, Russia
}

\begin{abstract}
The article discusses the tools as a means of influencing the regional authorities, used to implement regional policy aimed at forming an effective structure of the industry of the coal-mining region. There are five main groups of tools: economic, financial, organizational, legal and informational. Building an effective industrial structure is one of the most important tasks, the solution of which increases the efficiency and stability of the country's economy as a whole. This task should be solved from the regional level, since the general state of the Russian economy depends on the development of the regions. By the structure of the region's industry we mean the totality of all enterprises in the region with their sectoral focus and types of activity and the relationship between them. Such a structure is constantly in dynamics and is subject to changes and structural shifts.
\end{abstract}

\section{Introduction}

An efficient industrial structure contributes to an increase in the demand for industrial goods in the region, an increase in the revenue side of its budget and the strengthening of the competitiveness of existing industrial enterprises [1]. The criterion of efficiency is determined by a number of indicators, including: growth in labor productivity, capital productivity, a decrease in material consumption [3].

In order to determine the ways of development of the industrial complex of the region, as a rule, a system-functional or system analysis is used, which makes it possible to identify both internal and external factors of the functioning of the industry as a whole and its individual spheres and to reasonably choose the direction of economic development [1].

The formation of the structure of the region's industry is influenced by many factors, both internal and external. External factors include factors that cannot be controlled within the industry. These are natural-climatic, ecological, political, etc. Internal factors are determined by the internal natural, social, economic and political conditions for the development of the country. Internal backbone factors are determined by the nature and degree of interaction between enterprises. Internal backbone factors in relation to the regional industrial complex are: competitive ties, cooperation or interaction ties, innovative ties [6].

* Corresponding author: aafares@mail.ru 
The restructuring of the regional industrial complex is primarily associated with getting rid of "obsolete" and ineffective industries and the development of high-tech, modern types of management [1].

The subjects of management of the structure of the industry in the region are both the management bodies of the industrial complex at the regional level and the federal authorities and management. As world experience shows, the formation and development of the regional structure of industry should be carried out with the participation of the state, and not on the basis of self-regulation. In this regard, the most important tool for the formation and development of the structure of the regional industry is the regional state policy.

One of the most important tasks of the subject of managing the structure of industry in the region is to modify the structure of the region in order to build a more efficient structure. To implement this task, after carrying out a system analysis and identifying the potential for the development of an effective structure of the region's industry, as well as factors influencing its development, a regional policy for the development of the industrial complex is being developed, the achievement of the goals of which is carried out through various tools.

\section{Method used}

Tools used to achieve an efficient regional structure.

An economic instrument, according to [7], is understood as "methods and means of managing the economy, regulating economic processes and relations. Together, they form economic institutions".

A literature review shows [1-6] that researchers offer many different tools that can be grouped into 5 groups. It is also possible to distinguish between individual instruments according to the degree of direct influence of the controls. The strongest and most direct impact is provided by instruments aimed at liquidating a specific economic entity, the least powerful instruments aimed at stimulation.

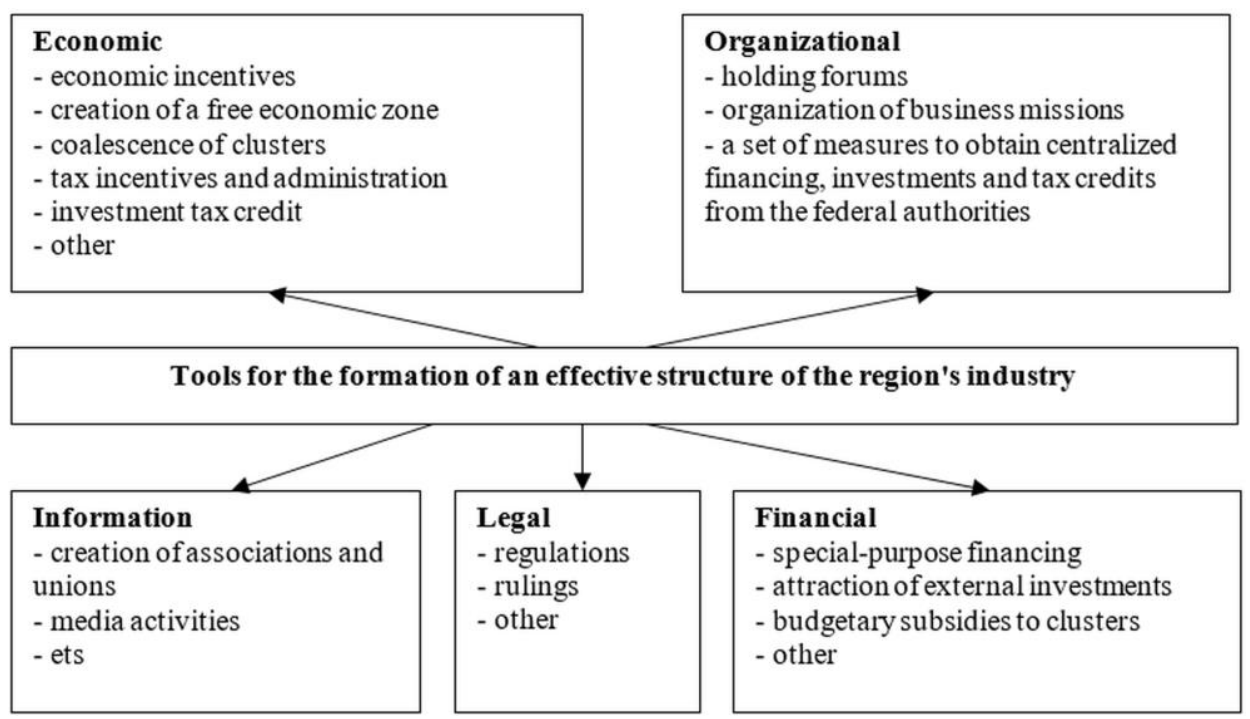

Fig. 1. Tools for the formation of an effective structure of the region's industry. 


\section{Results and Discussion}

Next, we will take a closer look at the instruments, dwelling in more detail on the economic ones.

1. Economic instruments. Include:

- economic incentive implies various measures to stimulate enterprises selected according to some criterion. For example, enterprises that implement strategically priority tasks, implement saving technologies. This measure implies the distribution of enterprises in the region into basic, prospective and subject to liquidation or partial closure (structurally depressive),

- tax incentives can be exemptions from the payment of a specific tax for all businesses or those selected according to some criterion, or the establishment of a preferential tax rate,

- tax administration carried out at the regional level is intended for tax regulation and control over the receipt of planned tax payments to the budget,

- investment tax credit is a deferral of tax payments provided in order to stimulate investment activity and renew the fixed assets of an enterprise on the basis of a loan agreement with the tax authorities [9],

- creation of a free economic zone, that is, a zone with certain tax or customs privileges. The free economic zone allows for the rapid growth of the region's industry by ensuring "soft" conditions. Free economic zones include offshore zones, integrated industrial zones, technopolises and technological parks, as well as foreign trade zones,

- initiation of bankruptcy proceedings presupposes the possibility of rescuing an enterprise in a crisis situation, or of its parts, as well as settlement of the bankruptcy enterprise's obligations.

Indirect tools for the formation of an effective structure of the region's industry are the creation of stable tax and production conditions for enterprises in the region.

2. Financial instruments include various instruments of government incentives and support [6]. Financial instruments make it possible to reorient investment flows, reduce support for enterprises with an outdated technological base and direct the main financing to innovative high-tech production. Financial instruments include: targeted financing (represents direct concessional short- and medium-term lending at the expense of the federal budget); attraction of external investments under the guarantees of the regional government; budgetary subsidies to clusters; government investments in the purchase of securities or the creation of property complexes;

3. Legal instruments include regulations; resolutions concerning the issues of legal regulation, tax legislation of the industrial structure of the region.

4. Organizational tools include a set of organizational measures to ensure the development of the structural complex of the region. Organizational tools include holding forums and organizing business missions.

Indirect tools for the formation of an effective structure of the region's industry are a set of measures to obtain centralized financing, investments and tax credits from the federal authorities.

5. Information tools include all activities to obtain and disseminate information that contributes to improving the efficiency of the industrial structure of the region. This is the creation of various associations and unions, etc., as well as various activities of the media.

\section{Conclusions}

Criteria for choosing tools for forming an effective structure of regional industry.

One of the important tasks to ensure the construction of an effective structure is the task of choosing the tools. In [9], many criteria are given that are applicable to a particular cluster. 
Let us generalize and select those criteria that can be applied to the regional industrial complex as a whole.

1. The cost of implementing activities within the framework of this method. This is one of the most important criteria, taking into account all the activities and resources that need to be applied to use this tool. This criterion can often act as the only one.

2. The depth of the impact on the regional structure. The set of tools depends on the required timing of the effect. Typically, for the required fast effect, power tools are used, and the duration of the effect is reduced.

3. The quantity and quality of problems solved by using this tool.

4. The presence and size of regional budgetary needs met by the use of a particular instrument.

5. Availability of information in the problem area of management. Takes into account where the information is collected from. Since a prompt response requires accurate and prompt information, if the use of a tool requires information that is a trade secret or confidential, then you have to abandon its use in favor of another tool.

6. Characteristics of the business entity.

7. The degree of influence of this business entity on the region's economy.

The application of these criteria will make it possible to make a reasonable choice of the tool for the formation of an effective structure of the region's industry. It should be noted that the decisive criterion for selection, in most cases, is financial, therefore, if a prompt response is required, it is sufficient to use only the first criterion [11].

The main condition for the sustainable development of the regional industrial complex and the implementation of an effective regional policy is the availability of efficient economic, financial, organizational, informational and legal instruments that are used to modernize and build an effective structure of the industrial complex [12-14]. Their number and combination may be different depending on the goals and objectives of the regional policy, the specific region of application and the specific current situation in this region. In this regard, the problem often arises of choosing one instrument from several, as well as the problem of assessing the effectiveness of the application of the selected instruments. The use of the above criteria will make it possible to make a reasonable choice of the tool and cut off obviously unfavorable options for the formation of an effective structure of the region's industry.

\section{References}

1. F.N. Abu-Abed, L.G. Naumova, Journal of mining and geotechnical engineering, 3(6), 21 (2019)

2. O.I. Gordeev, S.O. Gordeev, Development of the region's industry in the context of the transition to economic recovery: strategy, policy and means of support (NPK ROST, Saint Petersburg, 2007)

3. D.V. Manturov, Economics and Management, 5(139), 4 (2017)

4. Yu.V. Pavlovskaya, Belarusian Economic Journal, 3(60), 99 (2012)

5. F. Abu-Abed, A. Khabarov, E3S Web Conf. 41, 01028 (2018)

6. A.M. Tufetulov, Actual problems of economics and law, 4(8), 105 (2008)

7. D.F. Aliev, Scientific Review. Series 1: Economics and Law, 6, 11 (2010)

8. F. Abu-Abed, A. Ivanov, Bulletin of the Kuzbass State Technical University, 5, 69-76 (2020)

9. F. Abu-Abed, E3S Web Conf. 41, 01025 (2018) 
10. E.A. Mazilov, Development of the industrial complex in the context of modernization of the region's economy (ISERT RAN, Vologda, 2015)

11. B.A. Raisberg, L.Sh. Lozovsky, E.B. Starodubtseva, Modern economic dictionary (INFRA-M, Moscow, 2019)

12. R.F. Government, Concept of long-term socio-economic development of the Russian Federation for the period up to 2020 (Russian Newspaper, Moscow, 2007)

13. Tax Code of the Russian Federation (part one) of July 31, 1998 N 146-FZ (as amended on December 27, 2018)

14. F.N. Abu-Abed, A.R. Khabarov, Problems of Economics and Management of the Oil and Gas Complex, 5, 33 (2018) 